\title{
An Eco-Compensation Strategy in the Water Source Area: A Case for Southern Shaanxi in China
}

\author{
Zelin Wang ${ }^{1} \&$ Ruliang Zhang ${ }^{1}$ \\ ${ }^{1}$ School of Humanities and Social Sciences, Xi'an Jiaotong University, Xi'an, China \\ Correspondence: Zelin Wang, School of Humanities and Social Sciences, Xi'an Jiaotong University, Xi'an, \\ Shaanxi, China. Tel: 86-151-2901-1850. E-mail: zelin.wang@foxmail.com
}

Received: January 14, 2018

doi:10.5539/ass.v14n4p58

\author{
Accepted: March 5, 2018 Online Published: March 20, 2018 \\ URL: https://doi.org/10.5539/ass.v14n4p58
}

\begin{abstract}
The South-to-North Water Transfer Project (SNWTP) in China which is the world's largest water transfer project completed in 2014 is promoted as a strategy to mitigate water stresses in the northern China by the Chinese government and engineers. However, the ecological compensation of SNWTP in China has been slow and less for the people living in the water source area which was lost their opportunities to earn money; some had even lost their farmland. A key issue for SNWTP is to establish an eco-compensation system, define the compensation scheme, and make an effective economic compensation to the people living in the water source area. In this paper, we take the water source area of the Middle-Route project of SNWTP located in Southern Shaanxi including three cities called Hanzhong, Ankang and Shangluo as the research regions. Six factors are taken into consideration: (1) ecological losses, (2) economic losses and (3) ecological bonus in our eco-compensation strategy, as well as join two dynamic factors accounting in the calculation of ecological damage, (4) water quantity and (5) water quality. Besides, the total amount of compensation is changing over time. (6) Time scale factor is also used to simulate. In the article, we set three-time periods to calculate the different amount of compensation for the water source area. Finally, the Southern Shaanxi, supplied $70 \%$ water to Danjiangkou Reservoir, were analyzed by this model. We make full use of the reasonable eco-compensation strategy and try to solve actual problems of water source area and even provide a basis conception for the watershed protection and management.
\end{abstract}

Keywords: water source area, eco-compensation, South-to-North Water Transfer Project, Southern Shaanxi

\section{Introduction}

Water scarcity relative to human use has been acknowledged as one of the major problems facing humanity in the 21 st century(Cooley et al., 2014). Access to clean water is fundamental to sustainable development, in order to effectively overcome water shortages resulting from the uneven distribution of water resources and water demand (Sun et al., 2017). Many developing countries are utilized inter-basin water transfer projects, transferring water from water-rich areas to water-poor areas using inter-basin water transfers (Wilson et al., 2017). As water is a finite nature resource, has also considered as an intrinsically contested resource(Zwarteveen \& Boelens, 2014), these projects may also create water conflicts between water source areas and receiving areas. The South-to-North Water Transfer Project (SNWTP) in China is also no exception. As one of the most important inter-basin water transfer project implemented in the 21st century (Liu \& Zheng, 2002), SNWTP was designed to transfer water from southern China to northern China, aimed to support the sustainable social and economic development (Feng et al., 2007; Chen et al., 2011). As we know, the water-rich Yangtze River has long been regarded as a potential source for the arid northwest region of China and arid North China Plain (NCP) (Zhang, 2009). By transporting abundant water from Yangtze Basin to northern China, the historical dilemma of water distribution unevenness in China would be solved.

With the construction and formal use of SNWTP, numerous and diverse environmental problems have been arisen from the beginning. As we all know, China is under the centralized economic system, large-scale engineering projects were mostly undertaken by the central government, while the benefits went to local governments (Xiqing et al., 2002). However, the financial allocation by the Central Government cannot make up solved the impacts from the project to these related areas. "How and who may benefit from such projects while fleshing out the hidden inequalities in the distribution of benefits and impacts in both areas"(Domènech et al., 
2013). A common consensus is that we should established an inter-basin ecological compensation mechanism, but the disagreement at what and how ecological compensation mechanism would be "win-to-win", making both sides have been well accepted and easily implemented.

Currently, the world-wide payments for ecosystem services (PES) programs are not exactly suitable for China, PES has been defined as "a transparent system for the additional provision of environmental services through conditional payments to voluntary providers" (Tacconi, 2012). PES is always designed as an economic instrument for environmental conservation (Ma et al., 2017), many successful cases have implemented around the world, these programs promote the conservation of natural resources in the marketplace. Many Chinese scholars tried use PES method to solve the problem in the SNWTP. Nevertheless, China's current economic system is a collective public ownership economy, which quite different from the developed country of western countries. It is difficult to define the beneficiaries of the compensation and how to compensate them. Besides, even though the theoretical foundations of PES were set several decades ago, the practical implementation of these market-based instruments for managing natural resources has started rather recently. That means few successful cases are available for our reference to minimize environmental risks, ensure social equity, and sustain economic benefits (Wilson et al., 2017).

Proper scheme should be proposed to compensate the water source area reasonably to reduce the negative impact on the water transfer project. With the conception of "Ecology is also a productive force" (said by Jingping Xi, the present Chairman of China) is accepted by most people in China, we suggest establishing an ecological compensation mechanism which is more reasonable accept between water source areas and water receiving areas. Ballestero (2004) focus on the water transferable quantity and price provides a decision stochastic approach by simulating the recipient's demand curve and the donor's supply curve for transferable water which would encourage more sales of water rights by less efficient farmers, so that water being reallocated by the market among more efficient users on the Tajo-Segura aqueduct in Spain. (Ballestero, 2004). This method is more effective to balance the stakeholders between the water source areas and water receiving areas, but we also should take the social impacts in it. In order to supplying the transfer water, reach the standard on quality and quantity, Southern Shaanxi has been closing almost 400 companies, and planning to relocate 2.4 million mountainous people in 10 years. So, the opportunity loss and human capital loss also should calculate in the amount of eco-compensation. Jian Sun compared three methods: CCM, MVM and PAM, to determine the payment standard for an inter-basin water transfer project (Sun et al., 2017), given a reference value allowing for economic development in water receiving areas. However, in these methods have not considered the standard of compensation in different stages.

\section{Method}

The Middle-Route of the SNWTP have transferred water from Hanjiang and Danjiang to the Danjiangkou Reservoir, which are supplied to Hubei, Henan, and Hebei provinces, and ultimately to Beijing and Tianjin (Webber et al., 2017). These two sources of water are flowing through Southern Shaanxi, which is one of the largest tributaries in the middle reaches of the Yangtze River, contributing almost $70 \%$ water to Danjiangkou Reservoir. "National main functional area planning" (2010) was taken Southern Shaanxi as the Qinba biodiversity ecological function area and the water source areas of Middle-Route in SNWTP, has borne two ecological functions which are the biodiversity and water conservation (Haihong, 2012). The Southern Shaanxi is included three cities respectively, called Hanzhong, Ankang, Shangluo, were surrounded by mountains with fragile ecological environment and backward industrial development situation. In addition, the construction of water resources protected areas and ecological functional areas which set a higher threshold of an environmental access system also limit local economic development.

Ecological environment and human existence are integral to Southern Shaanxi, and we must find the breakthrough point between the development of the economy and the best combination of environmental protection, In order to protect water quality; some local development opportunities have been sacrificed in Southern Shaanxi, such as shutting down a large number of high polluting enterprises and establishing hydropower stations around the protected areas, even restricting the company type due to the highest standards for water source protection and environmental improvement. At the same time, much sewage and waste treatment facilities have been constructed, and thousands of people even have to move away from the water resource area to guarantee the water quality. A fact that cannot be ignored is that even in the developed areas at Southern Shaanxi, also belong to the relatively backward areas. A clear gap appears when compared with the Middle areas and the Northern areas. The latest data show that the population of Southern Shaanxi accounted for $22.2 \%$ of the Shaanxi province, but the realization of the GDP accounted for only $12.4 \%$. This leads to a most direct result, the outflow of labor. 
Establishing an eco-compensation mechanism is one of the efficient measures to solve the impacts produced by SNWTP, which clearly define the contributor, and make effective economic compensation to the Southern Shaanxi. The eco-compensation is included in the scope of compensation, which is the requirement to realize the organic unity of water resources economic benefit, social benefit and ecological benefit. It is also the favorable way to maintain the water ecosystem, protect the water resources, and coordinate the contradiction between the protection of the water source and the development of water source itself for the purpose to maximize the benefits from the water resources.

In summary, we analyze the current ecologic and economic status in Southern Shaanxi according to Damager Pays Principle, User Pays Principle, and Beneficiary Pays Principle, and develop an inter-basin compensation model by setting up the accounting framework and methodology, which is calculate the amount of ecological compensations to include three main factors: ecological loss, economic loss and ecological bonus. The human capital loss is taken as a part of ecologic loss. This requires a large number of planned compensations from government taxation and other aspects, such as corporate subsidies, education, medical and other items. Besides, ecological construction and conservation bring benefits not only for the water receiving area, but also for the water source area. Ecological bonus is still an important factor cannot be ignored in the eco-compensation evaluation. Using this model, the eco-compensation amount for Southern Shaanxi in the Middle-route project of SNWTP is more efficiently, effectively and easily to be calculated and implemented.

Based on our eco-compensation mechanism, the basic principles of assessments are the ecological loss and economic loss. According to Water Pollution Control \& Soil and Water Conservation Program on the watershed in The South Shaanxi, more financial expenditure is still needed to maintain water quality stability to meet national standards before 2020, or even longer. As the industrial structure adjusts, the benefits caused by this project will almost disappear by 2050 (Dong et al., 2011). We suggested to divide three stages from 2014 to 2050, which considered the ecological restoration cycle in it. The first stage (from 2014 to 2020) which focuses on adjust quantity and quality of the supplying water, in the second stage (from 2021 to 2030) we put attention on the ecological conservation and local economic development. Finally, from 2031 to 2050 we called it "Ecological restoration and benefit period", the amount of eco-compensation will be only focus on the transferable water. Additionally, the rural livelihood has arisen under the various ecological and environmental protection projects and measures (Chen et al., 2013). The residents have required for social justice and economic compensation to maintain sustainable livelihoods in water source areas.

\section{Methodology}

The Method section describes in detail how the study was conducted, including conceptual and operational definitions of the variables used in the study, Different types of studies will rely on different methodologies; however, a complete description of the methods used enables the reader to evaluate the appropriateness of your methods and the reliability and the validity of your results, It also permits experienced investigators to replicate the study, If your manuscript is an update of an ongoing or earlier study and the method has been published in detail elsewhere, you may refer the reader to that source and simply give a brief synopsis of the method in this section.

The South-to-North Water Transfer Project is different from the inter-basin water transfer in other countries. It does not follow the law of market economy, it is more likely a product of China's unique economic system, with obviously political characteristics. Therefore, the payment for ecological services (PES) policy (Goldman-Benner et al., 2012) successful used for other countries is not entirely suitable for China. Additionally, the quality of supplying water is affect greatly by the climate, natural disaster, water demand, and water pollution in the river basin(Dong et al., 2011). All those factors make the annual water supply is not stable. Some scholars calculate the amount of compensations from the perspective of water receiving area according to the quality of water supply. This is only a partial solution, which cannot completely cover the water area residents' sacrifices. In addition, Southern Shaanxi is restricted in the development of high-polluting industries and required to establish ecological reserves instead. This is not consistent with the market economy. In sum, the payment of ecological services from the affected area is unstable, while expenditure in the water area is sustained. Therefore, the eco-compensation should be calculated from the ecological loss and economic loss from the point of view of the water source areas.

In our criteria model, we take the ecological bonus into consideration. The criteria for Eco-compensation can be calculated as: the ecological loss plus economic loss in the water source area, minus ecological bonus:

$$
A_{E C}=F\left(L_{E G}, L_{E M}, B_{E G}\right)_{\text {criteria model }}
$$




$$
\stackrel{\text { yields }}{\longrightarrow} L_{E G}+L_{E M}-B_{E G}
$$

Where, $A_{E C}$ represents the amount of eco-compensation, $L_{E G}$ is the ecological loss and $L_{E M}$ is the economic loss, respectively. $B_{E G}$ means ecological bonus.

The SNWTP as a political decision-making resource allocation project, the eco-compensation accounting to consider the trade-off between the politics and economy, ecological compensation accounting standards for the water supply area as the starting point. For this reason, we must consider calculation the extra cost suffering by the project for the water source areas, as the exactly amount of the eco-compensation from the water receiving areas. The quality of transferable water as a dynamic factor used to measure compensation utility, the loss of ecological resources, the industry opportunity loss and local benefits and other aspects also should be considered in it. The proportion of the ecological compensation funds to each affected area are calculated by the actual water capacity of the affected area and the local GDP.

\subsection{Ecological Loss}

The Ecological loss mainly contains two parts: water loss and farm land loss. The water can be seemed as valuable products. In the transfer process, some areas have enlarged their benefits during with development, and have deprived the local economic development opportunities for the water transfer areas. Water ecological compensation to water resources for ecological products, water supply as a protector side, through the provision of ecological products and transactions to obtain revenue. In order to ensure the quantity and quality of the supplying water, to promote the sustainable development of water supply and ecological environment protection, the water source area has made a lot of human, material and financial resources to ensure the external economic effect of water resources continue to play(Li, Pang et al., 2010). According to the project request, the supplied water standards should meet or better than the water quality of class II. When the water-supply level is substandard, those water-supply should not be considered. Thus, the water loss could be represented by a function, $L_{W}\left(A_{w}, Q_{w}\right)$, in which the water quantity Aw and water quality $Q_{w}$ affect the amount of water loss. In the establishment of protected areas and resettlement process, many farm lands were levied. To calculate the loss of farm land, the variable $L_{F}\left(A_{L}\right)$ is introduced. The amount of ecological loss could be expressed by the following equation,

$$
L_{E G}=f\left(L_{w}, L_{F}\right) \stackrel{\text { yields }}{\longrightarrow} L_{W}\left(A_{w}, Q_{w}\right)+L_{F}\left(A_{L}\right)
$$

Where $L_{W}$ represents water loss in the water supply area, $L_{F}$ represents the farm land loss, $A_{w}$ represents the water quantity, $Q_{w}$ represents the totally quality of transferable water and $A_{L}$ represents the land loss amount, respectively.

Ecological losses we calculated to avoid duplication removing the accounting value of water resources themselves and only considered the ecological impact the land loss caused by the conversion of sloping land in Southern Shaanxi.

Where, $Q_{W}$ means annual amount of transferable water, $P_{A}$ means three cities in Southern Shaanxi tap water price. When the water quality up to standard delivery in Southern Shaanxi, we set $A_{W} \geq 1$.

Calculation of agricultural losses from the area of cultivated land in Southern Shaanxi, according to the policy document, the water area and the steep slope area with slope of more than $25^{\circ}$ in a certain area should be farmland and forest. there has:

$$
L_{F}=A_{L} \times \delta \times P_{V}
$$

Where $\mathrm{A}_{L}$ represent the quality of the land loss, $\delta$ is a coefficient for sloping farmland proportion in Southern Shaanxi, $\mathrm{P}_{V}$ represent the average price of the compensation per ha.

\subsection{Economic Loss}

Economic loss contains two parts: direct loss and industrial opportunity loss. Direct loss includes the funds that are invested in ecological construction and environmental protection in the water source area. The direct cost is mainly constituted by the ecological construction and conservation cost, the water environmental protection payment and pollution governance cost. Besides, to ensure water quality, the Southern Shaanxi has a huge bad influence on the primary and secondary industry, while having less influence on tertiary industry. We calculate industrial losses can be considered from three aspects, the first aspect is the increased sewage treatment fee of the industrial enterprises. The second aspect is the reduced industrial output and the last aspect is the restricted 
industrial enterprises stationed in GDP losses. Accordingly, the economic cost expressed as:

$$
L_{E M}=f\left(R_{U}, S_{U}, S_{P U}, R_{R}, S_{R}, S_{P R}\right) \stackrel{\text { yields }}{\longrightarrow}\left(R_{U}-S_{U}\right) \times S_{P U}+\left(R_{R}-S_{R}\right) \times S_{P R}
$$

Where, $R_{U}$ and $S_{U}$ respectively represent the per capita disposable income of urban residents in similar areas and water source areas, $S_{P U}$ represents the population of urban residents in the water source area, $R_{R}$ and $S_{R}$ respectively represent the per capita disposable income of rural residents in similar areas and water source areas, $S_{P R}$ represents the population of rural residents in the water source area.

\subsection{Ecological Bonus}

However, people lived in that protection area also benefit from the tourism, fresh air and more chances for attracting low-polluting industries. These benefits could be defined as "ecological bonus". we suggest evaluating the ecological bonus with a proportional parameter $(\beta)$ to exclude internal effect in the water source area, which is:

$$
B_{E G}=\left(L_{E G}+L_{E M}\right) \times \beta
$$

Ecological bonus will be the transfer of the central government to pay and benefit from the optimization of the industry part of the consideration, the current direction of the main development of Southern Shaanxi green ecological-based, good ecological environment brought about by tourism, agricultural and sideline products income.

In a summary, the first stage (from 2014 to 2020) and the second stage (from 2021 to 2030) we set a proportional parameter $(\beta) 10 \%$ and $20 \%$ respectively on calculated the amount of ecological bonus.

Finally, from 2031 to 2050 we called it "Ecological restoration and benefit period", with the continuous improvement of ecological restoration and the normal operation of environmental protection zones, the amount of the eco-compensation only considers annual transferable water. The annual amount of eco-compensation will be only focus on the quality of transferable water. Show as:

$$
\begin{gathered}
A_{E C}=L_{W}=Q_{W} \times P_{A} \quad\left(A_{W} \geq 1\right) \\
P_{A}=\frac{1}{3} \sum_{i=1}^{3} P_{i}
\end{gathered}
$$

With an example, according to statistics show that North Water Transfer Area 2015-- cumulative diversion 2016 annual 3.83 billion $\mathrm{m}^{3}$, of which $70 \%$ of the volume of water from the Southern region, so the quality of water loss in southern Shaanxi are $268 \mathrm{~m}^{3}$. the tap water price in China has included two parts: basic price and use fee, the unit price in Ankang is 2.07 CNY per ton, in Hanzhong is $1.65 \mathrm{CNY}$ per ton, in Shangluo is $1.75 \mathrm{CNY}$ per ton, we should state that the data of tap water price in these areas we used are collected from the government's official websites. Substitution of numerical values, available annual loss of water resources in Southern Shaanxi is about 488 million CNY per year.

\section{Results}

In the article, we focus on the improvement of the ecological environment for the residents and the benefits from the government. As the words say, "the ecological environment is also a productive force", the greatest ecological productivity is reflected in the tourism and the living standards of the residents.

(1) The first stage, begin in 2014 and end to in 2020.

Using the results of the third remote sensing survey in Shaanxi province, the total cultivated land area in Southern Shaanxi is 1.0378 million $\mathrm{hm}^{3}, 28 \%$ of the sloping land is more than $25^{\circ}$. According to the estimation of the output value per unit area, the crops grown in the sloping land of Southern Shaanxi are grain, oil, Chinese herbal medicine, tea, vegetables and fruit. However, according to the instability of market price and annual production, we follow the Shaanxi provincial government put in these areas returning farmland to forest compensation standards, 5,000 CNY per ha. Into the value, the farm land loss is about 1.45 billion CNY per year.

For the economic cost, we use the current domestic comparison with the calculation method, that is, the water source area and similar cities per capita disposable income comparison, compare the difference, and then multiplying the total population to get the amount of compensations, Economic losses can be considered from the government and the enterprises, the government level in the water conservancy, environmental protection and public facilities' management investment funds, enterprises include limited production, shut down the loss of GDP and harsh sewage charges. 
In this paper, we selected the Weinan City, which is relatively close to the development level in Southern Shaanxi, but not affected by the water source. As a reference year, 2015, the urban populations in Southern Shaanxi in 2015 are 4.0071 million people, the rural populations are 5.4031 million people. According to the statistics of Shaanxi Provincial Bureau of Statistics in 2015, the per-capita disposable income data in Southern Shannan and Weinan are respectively about 23,693 CNY and 25,472 CNY in urban areas, 7,979 CNY and 8705 $\mathrm{CNY}$ in rural areas. Taken the data into the formula, the economic loss is calculated a result about 11.08 billion CNY per year.

The amount of ecological bonus we have set a proportional parameter ( $\beta$ ) $10 \%$ on the first stage (from 2014 to 2020), there are about 1.25 billion CNY per year.

Finally, we could get a result for the first stage, according to our ecological compensation strategy, the amount of ecological compensations in the first stage of Southern Shaanxi are 11.28 billion CNY per year.

(2) The second stage, begin in 2021 and end to in 2030, the amount of eco-compensations we calculated as reference amount are 10.03 billion CNY per year.

(3) The last stage, begin in 2031 and end in 2050, the amount of eco-compensations we calculated estimated amount are 488 million CNY per year under our demonstration.

\section{Conclusions}

In this article, we suggest a new perspective to measure the standard of eco-compensation. Three main factors, ecologic loss, economic loss and ecologic bonus, are taken into account, two unstable coefficients called water quantity and water quality put toward for an accurate calculation. In addition, we also divided three-time periods to calculate the reality amount of compensation. According to our article, the economic loss, especially in the loss of development opportunity, has considered the main loss. Many planned compensations require for government taxation and other aspects, such as corporate subsidies, education, medical and other items. Using this computational mechanism, the compensation amount to the Southern Shaanxi due to SNWTP will be easier to calculate. Combine the principle of social fairness and justice. It should not only maintain the local ecological environment, but also promote the optimization of the local industrial structure and promote the economic development.

\section{Acknowledgments}

We are very grateful to Shaanxi Provincial Environmental Protection Agency for help me collect data and give me more convenient to review residents.

The data used in this article are from Shaanxi Provincial Bureau of Statistics, as well as the official announcement of local government information.

\section{References}

Ballestero, E. (2004). Inter-basin water transfer public agreements: A decision approach to quantity and price. Water resources management, 18(1), 75-88. http://dx.doi.org/10.1023/B:WARM.0000015390.39862.b9

Chen, L., Tian, H., Zhang, X., Feng X., \& Yang, W. (2011). Public attitudes and perceptions to the West-to-East Pipeline Project and ecosystem management in large project construction. International Journal of $\begin{array}{lllll}\text { Sustainable Development } \& \text { World } & \text { Ecology, }\end{array}$ https://dx.doi.org/10.1080/13504509.2011.611189.

Cooley, H., Ajami, N., Ha, M.-L., Srinivasan, V., Morrison, J., Donnelly, K., \& Christian-Smith, J. (2014). Global water governance in the twenty-first century. The world's water, Springer, 1-18. http://dx.doi.org/10.5822/978-1-61091-483-3_1

Domènech, L., March H., \& Saurí, D. (2013). Contesting large-scale water supply projects at both ends of the pipe in Kathmandu and Melamchi Valleys, Nepal. Geoforum, 47, 22-31. http://dx.doi.org/10.1016/j.geoforum.2013.02.002.

Dong, Z., Yan, Y., Duan, J., Fu, X., Zhou, Q., Huang, X., Zhu X., \& Zhao, J. (2011). Computing payment for ecosystem services in watersheds: An analysis of the Middle Route Project of South-to-North Water Diversion in China. Journal of Environmental Sciences, 23(12), 2005-2012. http://dx.doi.org/10.1016/S1001-0742(10)60663-8

Feng, S., Li, L. X., Duan, Z. G., \& Zhang, J. L. (2007). Assessing the impacts of South-to-North Water Transfer Project with decision support systems. Decision Support Systems, 42(4), 1989-2003. http://dx.doi.org/10.1016/j.dss.2004.11.004. 
Goldman-Benner, R. L., Benitez, S., Boucher, T., Calvache, A., Daily, G., Kareiva, P., Kroeger, T., \& Ramos, A. (2012). Water funds and payments for ecosystem services: practice learns from theory and theory can learn from practice. Oryx, 46(1), 55-63. http://dx.doi.org/10.1017/S0030605311001050

Haihong, X. (2012). The Ecological Economization in South Shaanxi of the Middle Route South-to-North Water Transfer Project. Ecological Economy, 2, 021.

Li, H.-e., Pang, M., Xiao, Y., \& SHI, S.-j. (2010). A study on ecological compensation quantity based of water resource value in Shanxi water source area. Journal of Northwest University (Natural Science Edition) 40(1), 149-154.

Liu, C., \& Zheng, H. (2002). South-to-north water transfer schemes for China. International Journal of Water Resources Development, 18(3), 453-471. http://dx.doi.org/10.1080/0790062022000006934

Ma, Z., Bauchet, J., Steele, D., Godoy, R., Radel, C., \& Zanotti, L. (2017). Comparison of Direct Transfers for Human Capital Development and Environmental Conservation. World Development, 99, 498-517. http://dx.doi.org/10.1016/j.worlddev.2017.05.030.

Sun, J., Dang, Z., \& Zheng, S. (2017). Development of payment standards for ecosystem services in the largest interbasin water transfer projects in the world. Agricultural Water Management, 182, 158-164. http://dx.doi.org/10.1016/j.agwat.2016.06.025.

Tacconi, L. (2012). Redefining payments for environmental services. Ecological Economics, 73, 29-36. http://dx.doi.org/10.1016/j.ecolecon.2011.09.028

Webber, M., Crow-Miller, B., \& Rogers, S. (2017). The South-North water transfer project: Remaking the geography of China. Regional Studies, 51(3), 370-382. http://dx.doi.org/10.1080/00343404.2016.1265647.

Wilson, M. C., Li, X.-Y., Ma, Y.-J., Smith, A. T., \& Wu, J. (2017). A Review of the Economic, Social, and Environmental Impacts of China's South-North Water Transfer Project: A Sustainability Perspective. Sustainability, 9(8), 1489. https://dx.doi.org/10.3390/su9081489.

Xiqing, C., Dezhen, Z., \& Erfeng, Z. (2002). The south to north water diversions in China: review and comments. Journal of Environmental Planning and Management, 45(6), 927-932. https://doi.org/10.1080/0964056022000024415.

Zhang, Q. (2009). The South-to-North Water Transfer Project of China: Environmental Implications and Monitoring Strategy. JAWRA Journal of the American Water Resources Association, 45(5), 1238-1247. http://dx.doi.org/10.1111/j.1752-1688.2009.00357.x

Zwarteveen, M. Z., \& Boelens, R. (2014). Defining, researching and struggling for water justice: some conceptual building blocks for research and action. Water International, 39(2), 143-158. https://doi.org/10.1080/02508060.2014.891168.

\section{Copyrights}

Copyright for this article is retained by the author(s), with first publication rights granted to the journal.

This is an open-access article distributed under the terms and conditions of the Creative Commons Attribution license (http://creativecommons.org/licenses/by/4.0/). 